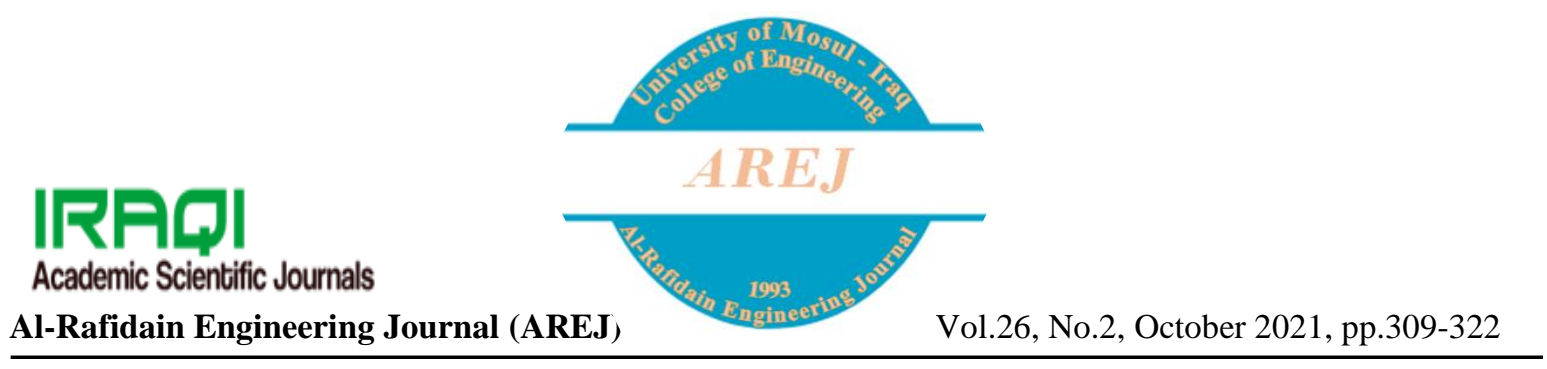

\title{
A Review of Digital Image Fusion and its Application
}

\author{
Zahraa T. Al-Mokhtar \\ Farah N.Ibraheem \\ zahraatalal@umosul.edu.iq \\ Hassan F. Al-Layla
}

Computer Engineering Department, Collage of Engineering, University of Mosul

Received: 8/8/2020

Accepted: 3/5/2021

\begin{abstract}
Image Fusion is applied to get back a group of data from two or more than two images and put it into one image to create additional wealthy information and profitable more than any of the input data that led to increase the features and performance of information. The quality of the resultant data relies on the implementation of the process. Image fusion is excessively utilized in stereo camera fusion, medical application, manufacture process monitoring, electronic circuit design and inspection, complex machine diagnostics and in intelligent robots on assembly lines. This study displays a literature review on different types of algorithm and theories which apply on images. Many quality criteria have debated to do a brief comparison of these methods. The applications of image fusion are showed in this paper.
\end{abstract}

\section{Keywords:}

Image fusion; DWT; SWT;DCT; Principal Component Analysis.

This is an open access article under the CC BY 4.0 license (http://creativecommons.org/licenses/by/4.0/). https://rengj.mosuljournals.com

\section{INTRODUCTION}

Image fusion Technique takes excessive and complementary information from the input signals "more than one image "to produce an output signal "one image " which is further suitable for the aim of human observation. The accuracy and all information of the resultant output are raised. Image Fusion inspire many characteristics on remote sensing, medicine, computer vision, military target detection and identification that it has conquered to the blind spot in different fields of science and technical distresses. Image fusion technologies have greatly developed the accuracy of the identification[1].

This paper is organized as follows: Section two display a Literature Review of image fusion Techniques. Section three is for categories of Image Fusion while section four describes many type of image fusion technique. A brief explanation of the types of Image Quality Metrics of Fusion algorithms are explained in section five. Section six listed the application of image fusion ,The conclusion is discussed in Section seven.

\section{LITERATURE REVIEW}

image fusion algorithms begins to play an important role in many application such as remote sensing[2-5] which are depending on enhancement in hyperspectral imagery [6] and deep convolution neural network [7-8]. Another major application of image fusion is in the medical and biological engineering[9], disease identifications[10-12]. The utilization image enhancement as pattern selective color fusion is discussed in [13-14].Fuzzy logic is another method of image fusion [15-16]. Genetic applications are depending on image fusion to improve the quality of output [17]. De-noising approaches have a great part of using image fusion to smooth and treatment the damage of the result [18]. The theories and transformations which are used to apply the image fusion is very diverse like wavelet transform [19-25] and IHS Transformation [26], Discrete cosine transform[27-28], curvelet transform based on linear dependency test [29].

Another side of approaches are depending of different focus depth of input image which called multi-focus for image fusion are described in [3032]. Other researches are explained the filtration operation, modeling and segmentation for image [33-37] While ICA independent component 
analysis can also be used for executing a fusion in a series of images [38].

\section{THE CLASSIFICATION OF IMAGE FUSION}

Image fusion theories can be divided into two types [39-42]:

1. Type one: relies on how the input images were obtained.

2. Type Two: relies on the levels of processing.

\subsection{Depends on how the input images were \\ Gained}

1. Multi sensor method the input signals are picked by various sensors.

2. Multi temporal method: collects the signals picked at different times in order to discover any alteration amidst them

3. Multi focus method: this kind of image fusion depends on three dimensional scene combined over and over with different lengths of focal.

\subsection{Depends on the Level of Processing}

1. Pixel level fusion: This kind of image fusion is created based on the data which it is fixed at a group of pixels in input signals to increase the accuracy of implementation [46-48].

2. Block level fusion: Based on the neighborhood points of the information provided.

3. Feature level fusion: It turns on the distinguished countenance of the data like pixel Intensities, size and edge. These features of the input images are combined.

4. Decision level fusion: The results from multiple algorithms are joined to get a final decision image. At the beginning, input images are managed then the gained information is collected to apply the decision rules. The decision level methods are dealing with symbolic implementation of images [39]. The levels of image fusion are illustrated in Fig.1.

4. Multi view method: the images are incorporated at the same format and the same
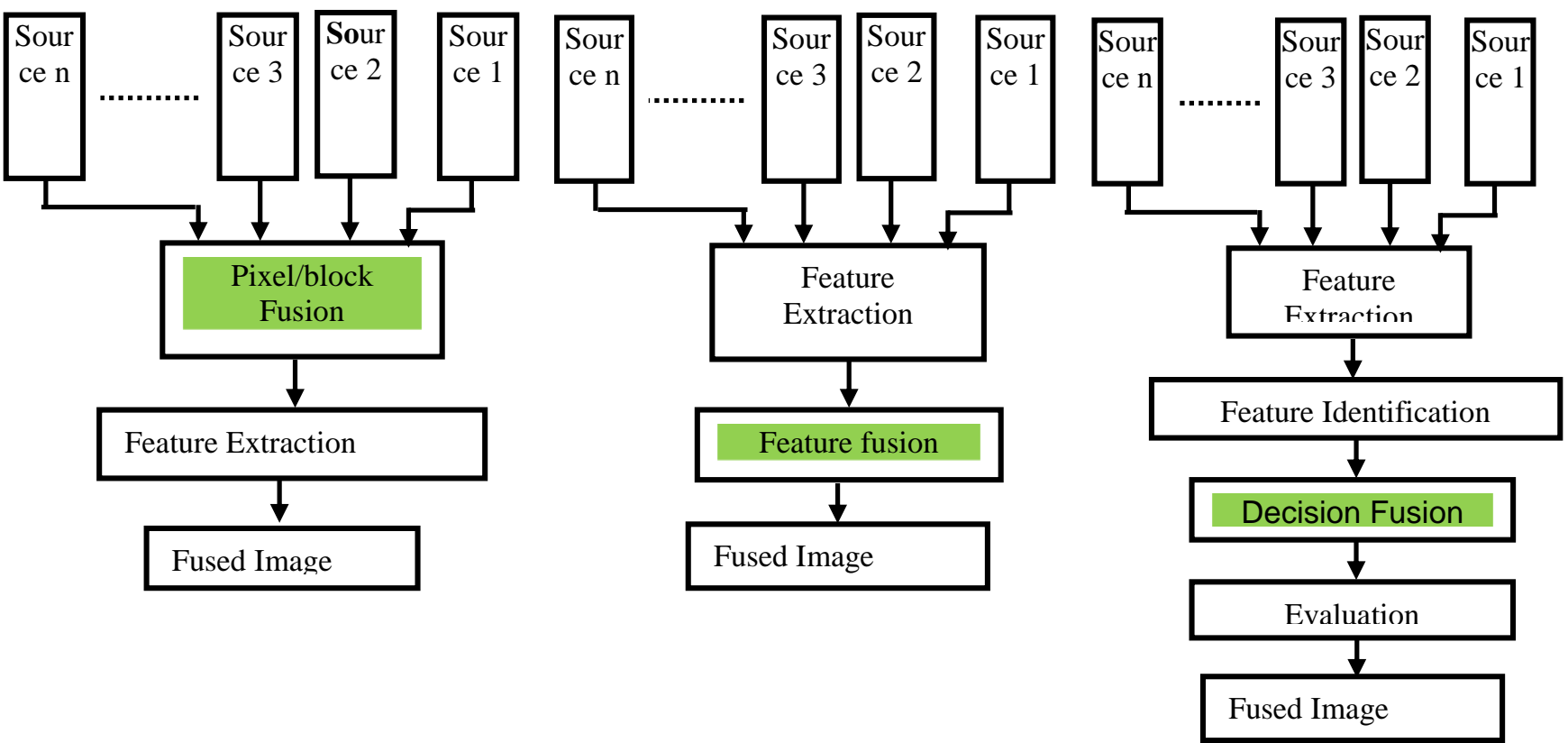

Fig.1 The operation Level of Image Fusion.

time but are mixed in different viewpoints.[43-

45]. 


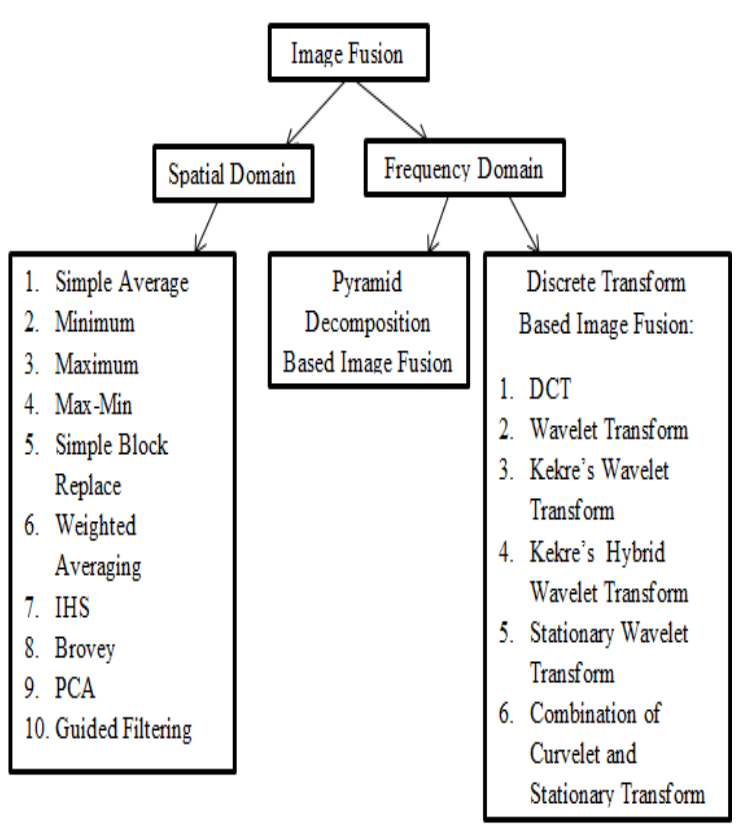

Fig.2 Image fusion techniques

\section{IMAGE FUSION TECHNIQUES}

Image fusion is categorized into two parts as shown in figure 2. :

1. Spatial domain.

2. Frequency domain.

\subsection{Simple Image Fusion Technique}

\subsubsection{Averaging Technique:}

This is the simplest spatial domain module. The average technique decreases the resultant image quality by introducing noise into fused image. This leads to reduce an unwanted side effect like reduced contrast [43]. The resultant image is applied by equation 1 [32].

$$
F(\mathrm{i}, \mathrm{j})=\frac{\mathrm{A}(\mathrm{i}, \mathrm{j})+\mathrm{B}(\mathrm{i}, \mathrm{j})}{2}
$$

Where

$A(i, j), B(I, j)$ are input matrixes and $F(i, j)$ is the output matrix.

This technique does not give guaranteed to have a fine data from the group of images.

\subsubsection{Greatest Pixel Value Technique:}

This technique selects the greatest value from corresponding pixels. The fused image is obtained as [41].

$$
F(i, j)=\sum_{i=0}^{m} \sum_{j=0}^{n} \max (A(i, j) B(i, j))
$$

Where

$A(i, j), B(I, j)$ are input matrixes and $F(i, j)$ is the output matrix.
The fused image is highly concentrated from the input image. This technique is influenced by the blurring action that impacts the contrast of the image[43].

\subsubsection{Minimum Pixel Value Technique:}

The minimum value of intensity is chosen and is inserted the resultant data in the fused image. The fused image can be calculated by the following equation [32].

$F(i, j)=\sum_{i=0}^{m} \sum_{j=0}^{n} \min (A(i, j) B(i, j))$

Where

$A(i, j), B(I, j)$ are input data and $F(i, j)$ is the output data.

\subsubsection{Max- Min Technique:}

The minimum and maximum values of input images are chosen and the averages are calculated. The final value is saved as the values of the pixel in the output data [32].

\subsubsection{Weighted average Technique:}

This method is suggested by Song et. Al [43]. The different weights are allocating to all input images and the Pixels $(\mathrm{x}, \mathrm{y})$ of fused image are applied by computing weighted sum of all corresponding pixels in input images. It improves the detection reliability but increases the signal to noise ratio (SNR)of the fused image [47]:

$\mathrm{F}(\mathrm{i}, \mathrm{j})=\sum_{\mathrm{i}=0}^{\mathrm{m}} \sum_{\mathrm{j}=0}^{\mathrm{n}} \mathrm{W} * \mathrm{~A}(\mathrm{i}, \mathrm{j})+(1-\mathrm{W}) * \mathrm{~B}(\mathrm{i}, \mathrm{j})$ (4)

Where

$\mathrm{A}(\mathrm{i}, \mathrm{j}), \mathrm{B}(\mathrm{i}, \mathrm{j})$ are input data and $\mathrm{F}(\mathrm{i}, \mathrm{j})$ is output data and $\mathrm{W}$ is the weight factor.

\subsubsection{The Principal Component Analysis Technique (PCA):}

Principal component analyses "PCA" is a vector space conversion applied to decrease the multi-dimensional information groups to a lower dimension. PCA is a plain and useful of the correct eigenvector based multivariate analyses, due to detect the internal features of information in an equitable way [32].

The Principal component analysis is utilized to convert the correlated numbers into uncorrelated numbers. At first, the PCA is used to get a maximum alteration with the along of direction. Second, the principal components are specified in a subspace vertical to a first within this subspace; this component dots the way of maximum change. The step three of the principal components is executed depending on the direction of maximum difference in a subspace perpendicular to the first, two and so on. This algorithm is also known as Karhunen-Loève or the Hotelling transform [45]. This technique does 


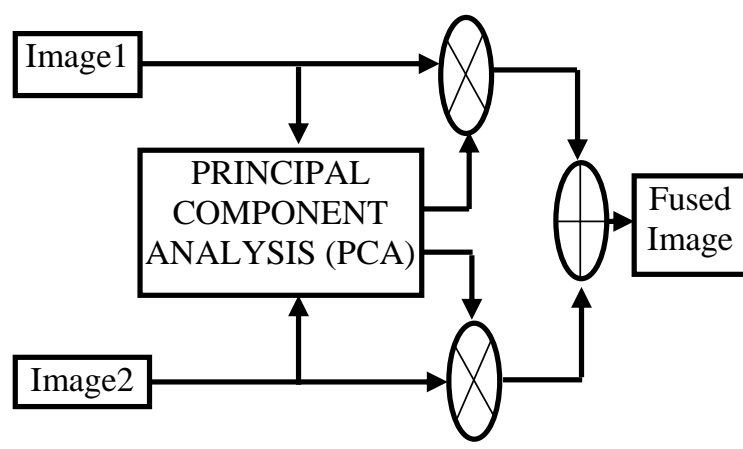

Fig.3 The flow diagram in image fusion scheme employing PCA.

not have a fixed set vectors like "FFT", "DCT "and wavelet etc. and its basis vectors based on the data set $[1,13]$. The PCA is very easy to apply for image fusion and output fused images have high spatial quality. But the results in spatial degradation.

The flow diagram of PCA image fusion algorithm is shown in Fig.3. Image fusion algorithm using PCA is characterized in fig. 4 [45]:

\subsubsection{High Pass Filter Technique (HPF):}

High Resolution Multispectral Image "HPMI "is made by applied high pass filtering. A high frequency data which is produced by High Resolution Panchromatic Image "HRPI "is collected with a low resolution multispectral image to acquire the fused 2D signals. This algorithm is implemented either by using a high pass filter with HRPI or by subtracting Low Resolution Panchromatic Image "LRPI "from original HRPI [40].

\subsubsection{Brovey Transform Technique:}

It is known as "the colour normalization transform "[46]. The mean advantage of Brovey Transform is the simplicity and grants attractive images and high contrast RGB image can be obtained by Brovey Transform [43].

This method is not applied for the original scene radiometry and bounded to only three bands [48]. Brovey Transform Technique can be applied by the following equation.

Fusion $_{\mathrm{i}}=\frac{\text { band }_{\mathrm{i}}}{\sum \text { band }_{\mathrm{n}}}$ X PAN

Where

Fusion $_{\mathrm{i}}$ is the output image, $\mathrm{i}=1,2,3$.

\subsection{PYRAMID TECHNIQUE}

A pyramid method can operate a lot of data at various scales which is representing together the original image. In general, this method consists of three major stages [49-50]:

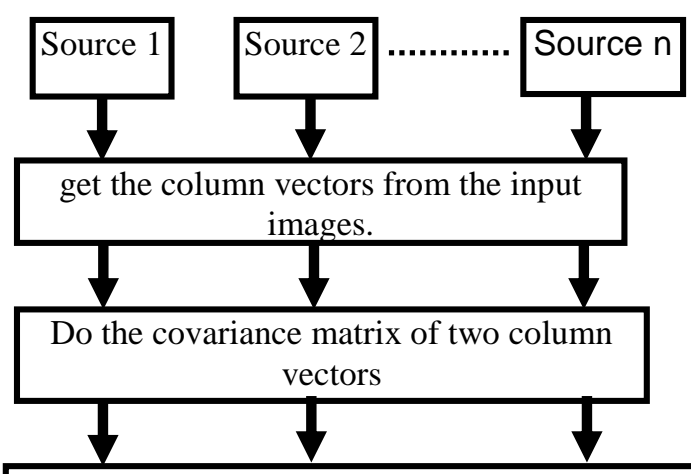

Calculate the Eigen values and Eigen vectors Of the covariance matrix

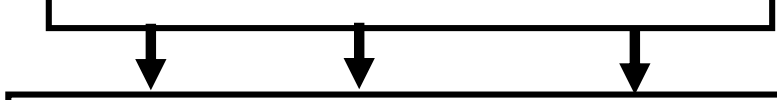

Divide each element with mean of Eigen vector to find the normalized larger Eigen value

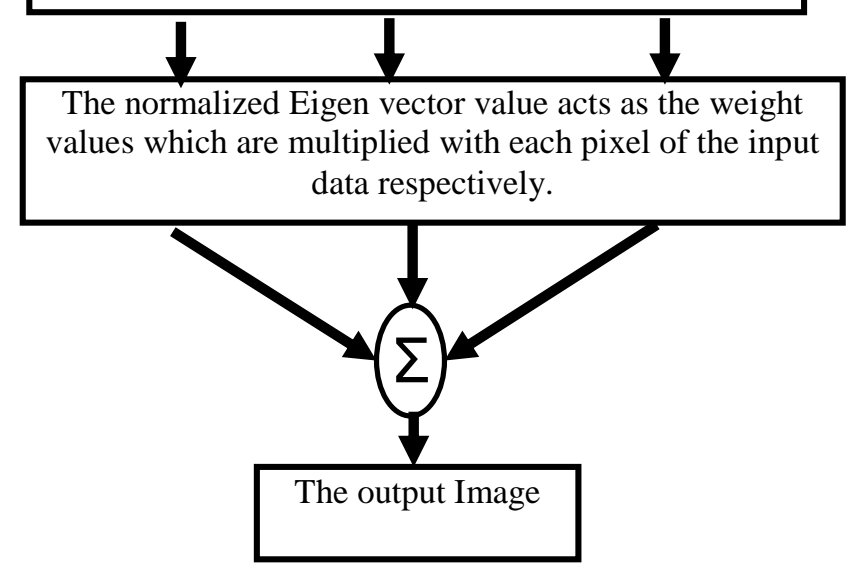

Fig.4 The block diagram of PCA algorithm.

\subsubsection{The Decomposition Stage:}

The operation of this stage is produced in succession at every steps of the fusion. The levels of fusion are determined early. This stage consists of the following steps.

1-The input images are filtered through a low pass filter.

2- Change the size of the signals to half size by using the decimated algorithm [47].

These steps are repeated number of times.

\subsubsection{The maximum-minimum/ average Stage} This step are defined as second stage of Pyramid technique which are using the final decimated input matrices, and a new image matric is calculated either by selecting minimum or maximum or taking average.

\subsubsection{Re-composition Stage:}

The resultant image which is created at each level of decomposition is used in the re- 


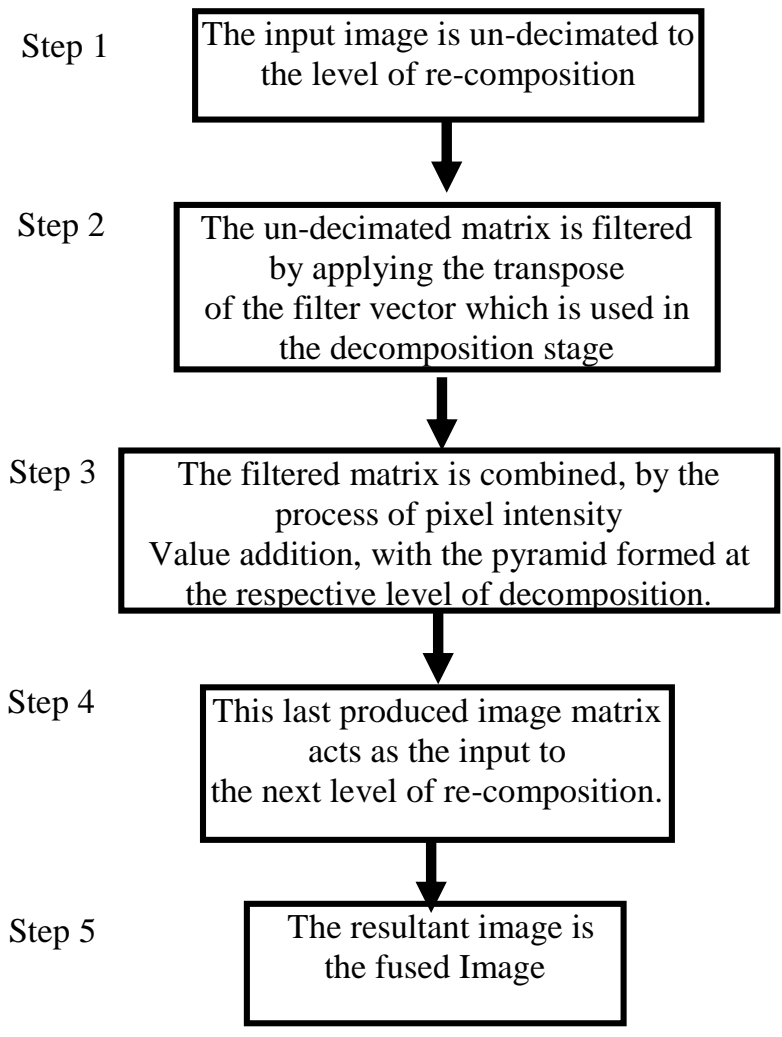

Fig.5 The block diagram of pyramid technique. composition operation. The re-composition consists of many steps which are refined at many numbers of times as in the decomposition operation. These steps [32] as stated in fig.5.

Many types of pyramid fusion Techniques are shown below:

1. Laplacian Pyramid

2. Gradient pyramid

3. Morphological pyramid

4. Ratio of low pass pyramid

5. Contrast pyramid

6. Filter-subtract-decimate pyramid.

The disadvantage of spatial domain methods is that they perform spatial distortion in the fused image. Spectral distortion has negative values while we go for further processing. Spatial distortion can be very well replaced by frequency domain theories on image fusion. The discrete transform and multi resolution analysis becomes a very efficient tool for analyzing and calculating in image fusion [43].

\subsection{Discrete Transform Based Fusion \\ Technique}

The Discrete Transform based fusion can be described by the following scheme in fig. 6 [51]:

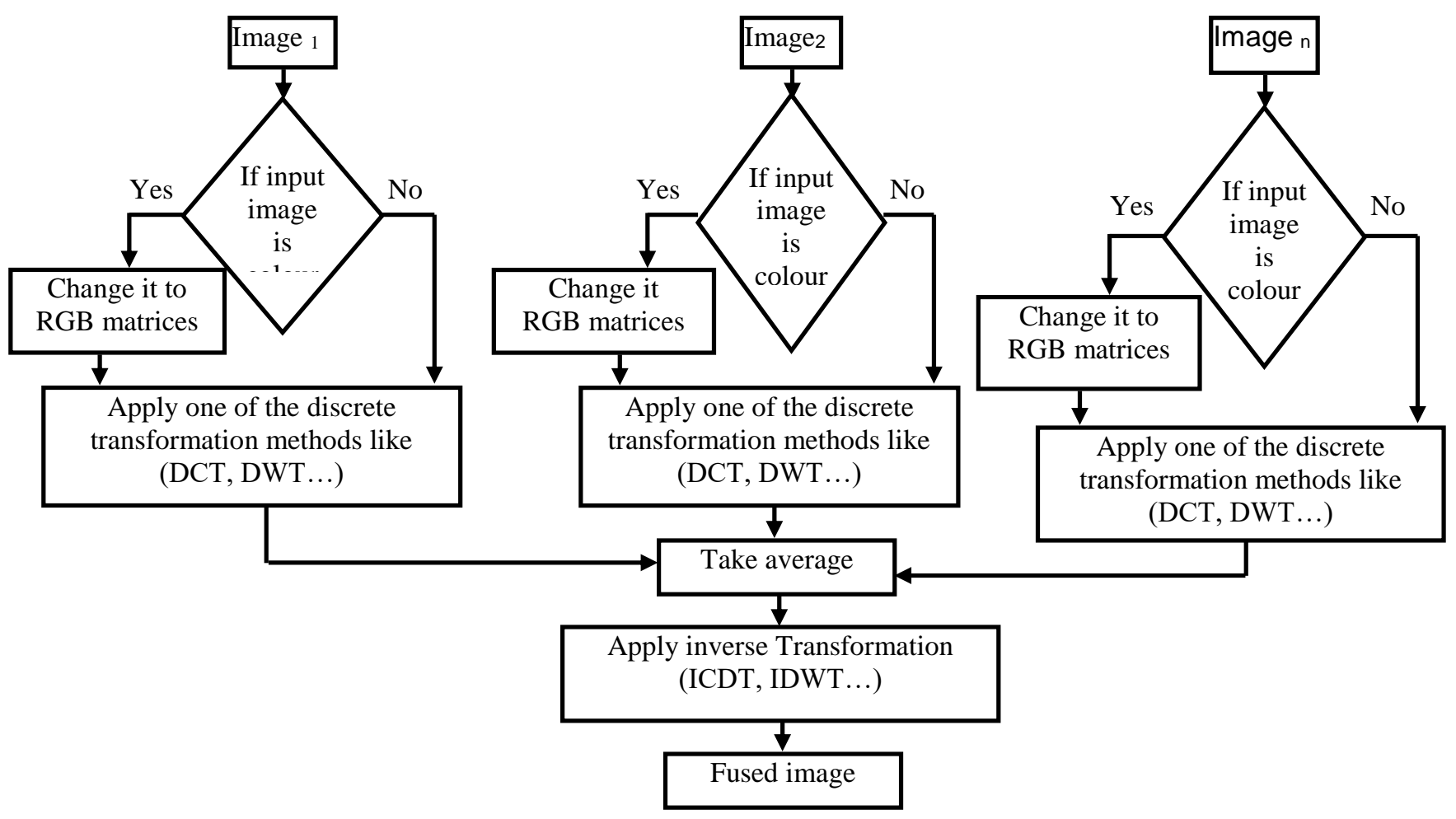

Fig.6 The block diagram of Transform based pixel level mage fusion scheme. 


\subsubsection{Discrete Cosine Transform:}

A DCT is applied to represent an order of restricted data bounded as far as capacities of cosine at different frequencies. The DCT is widely used as a part of computing image setting. The Universal DCT coefficients are crowded in the low repeating district. The DCT coefficients are calculated for every blocks of input image [46]. apply image fusion are DCT av, DCTma, DCTah, DCTch, DCTe and DCTcm. All these method applied the main steps of Image fusion using 'DCT' with some little different. The steps of DCT image fusion are as follows:

1. Divide input images into nonoverlapping blocks of size $\mathrm{N} \times \mathrm{N}$.

2. Repeat following steps for every block.

a. Compute DCT coefficients for each block.

b. Apply fusion rules to get fused DCT coefficients.

c. Apply IDCT on the fuse

in DCT Techniques like DCTav, DCTma, DCTe and DCTcm methods, The DC components are averaged together. But in some method like DCTah and DCTch methods, the lowest AC. Compnents including DC coefficients are averaged. but in DCTma method, AC coefficients are chosen based on largest magnitude. DCTcm method is calculating The AC coefficients based on Maximum contrast measure while the DCTe method is selecting AC coefficients according to the largest energy frequency band.

The DCT's techniques do not work well if the block size of the divided input image less than $8 \times 8$. The DCTav is very simple and basic image fusion technique in DCT domain. And DCTe, DCTmx performed well in image fusion domain. These methods are very simple and can be applied for real time applications [ 28].

\subsubsection{Discrete Wavelet Transform:}

Discrete wavelet transform is multiresolution decomposition modules which supply a multi-mode to represent the image features by various frequency sub-bands in multi-scale [49]. When the forward DWT is implemented, the approximation and detail coefficients are calculated separately. The output image can be displayed as four Sub band images "LL, LH, HL and HH". As shown in fig,.7 [50].

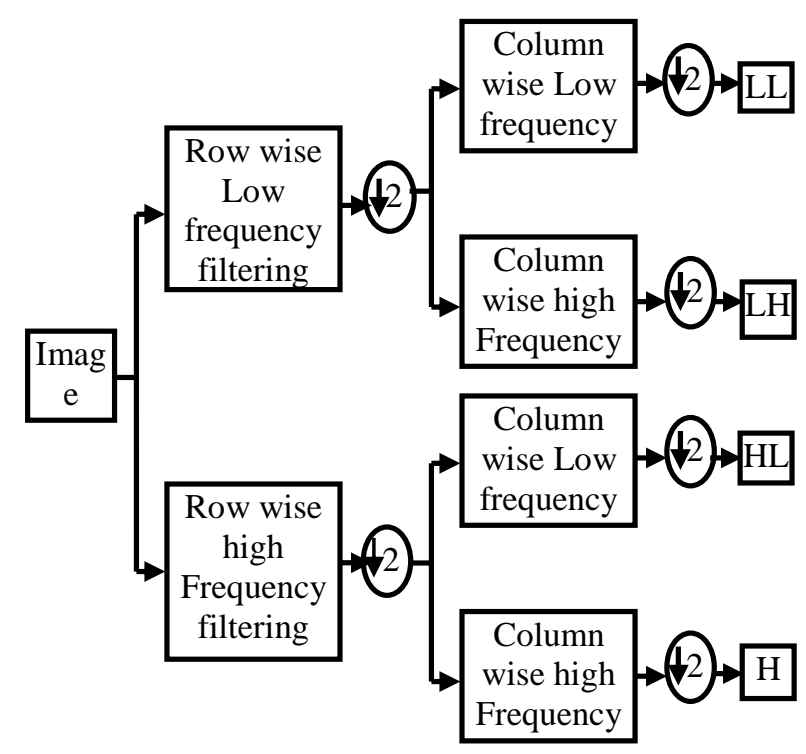

Fig.7 The 2D DWT decomposition.

\subsubsection{Stationary wavelet transforms:}

Stationary Wavelet Transform "SWT "can be derived from the Discrete Wavelet Transform but the down sampling operation is deleted. the SWT is translation-invariant. The two dimensional module of SWT can be explained in Fig.8 [51-53].

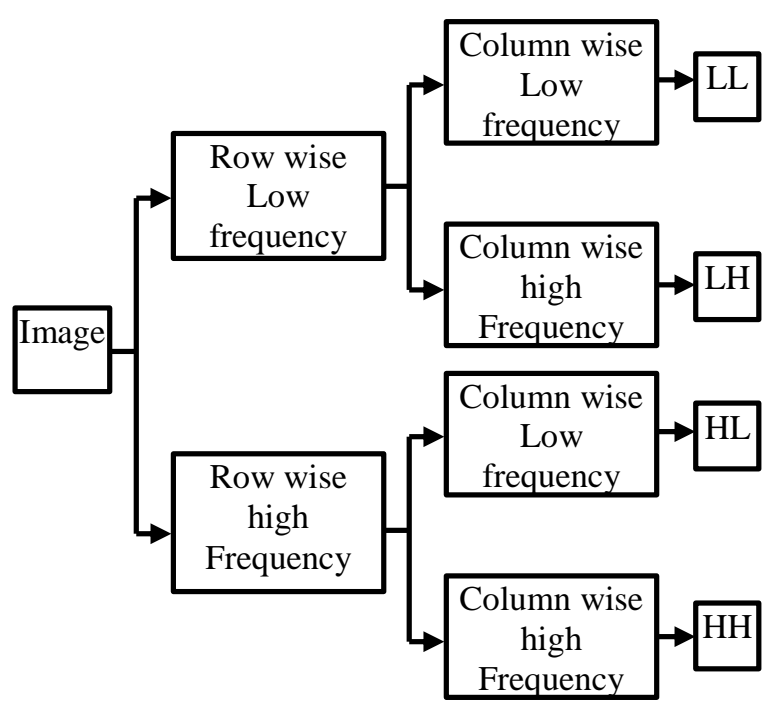

Fig. 8 The 2D SW decomposition.

\subsubsection{KEKRE'S TRANSFORM :}

Kekre matrix is derived from Kekre's LUV color space matrix. The condition of the most other conversions matrices which have to be in powers of 2 is not demanded in Kekre transform. But the 


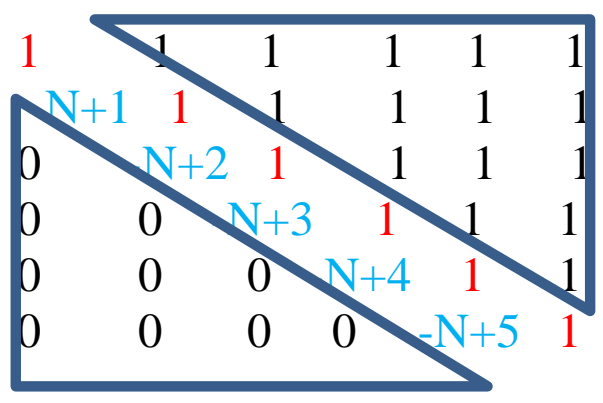

Fig. 9 The 6X6 Kekre's transform matrix.

Kekre matrix can be calculated depending on the following equation $[54,55]$.

$$
\begin{aligned}
& \mathrm{k}_{\mathrm{xy}}= \\
& \left\{\begin{array}{cc}
1 & : \mathrm{x} \leq \mathrm{y} \\
-\mathrm{N}+(\mathrm{x}-1) & : \mathrm{x}=\mathrm{y}+1 \\
0 & : \mathrm{x}>\mathrm{y}+1
\end{array}\right.
\end{aligned}
$$

The above equation can be represented as shown in fig. 9. This means the upper triangle and diagonal values of Kekre's conversion are 1, while the lower triangle except the elements just below diagonal is zero [51].

\subsubsection{KEKRE'S HYBRID WAVELET MATRIX Technique:}

This method of transformation is adding the values of two various orthogonal conversion wavelets to employ the intensities of wavelets. A size of hybrid transform matrix are $\mathrm{NxN}$ which called "TAB ". This transform can be produced from two matrices $A$ and $B$ with sizes pxp and qxq respectively. The $\mathrm{N}=\mathrm{p}^{*} \mathrm{q}=\mathrm{pq}$ as shown in figure 10 [28]. A first row of the hybrid matrix can be produced by multiplying every value of first row of A with every value the columns of the B. another row of hybrid matrix are the second row of the matrix A which are shifted rotate after being appended with zeros as shown in fig.9.

The chosen one of the image fusion techniques depends on the application which fused image are applied, But knowing the advantage and disadvantage of each one of the image fused techniques as shown in Table .1 can help to determine which one of them
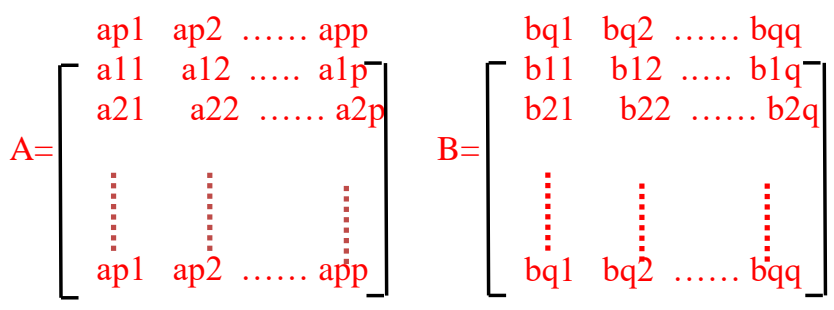

Fig.10 The Kekre's Hybrid wavelet matrix. more suitable for specific application.

\section{Image Quality Metrics}

The estimation methods of images quality can be organized into two types according to exist reference image: Full Reference Methods "FR "and No Reference Methods "NR". In first estimation method, the features are calculated depends on an original image which is assumed to be perfect in quality. Another type of estimation methods do not depends on original image [56].

\subsection{Full Reference Image quality assessment (FR- IQA)}

The efficiency of fusion modules can be calculated using the following standardization which is illustrated in Table.2. Assume $A$ is the input references data, B is the output data. $i, j$ is the pixel index of row and column respectively. The dimension of the image is $\mathrm{Mx} \mathrm{N} \mathrm{[57-59].}$

\subsection{NO REFERENCE IMAGE QUALITY ASSESSMENT (NR-IQA)}

The "NR-IQA "or "blind "quality criteria approach is very useful in which the reference image is not available. There are some NR-IQA criteria as shown in the following table 3 [63-65].

\section{APPLICATIONS AND USES OF IMAGE FUSION}

1) It is utilized in satellite or remote space due to suitable view of satellite vision [66-68].

2) It is employed in medical image to analysis the disease through imaging vision depends on frequency and spatial resolution [69-72].

3 ) It is utilized in military applications to discover the threats and other work impedance [73,74].

4) In robotics applications, the fused image is mostly utilized to detect the frequency divergences in the image [75-78].

5) It is employed in artificial neural network where a centric length according to wavelength conversion [79-83].

6) Some application of image fusion deal with enhancement road map extraction which plays an important rule especially in big city in high resolution image with focusing on edge extracted by using some theory of image fusion [84]. 
Table 1:Comparison of Image fusion Techniques

\begin{tabular}{|c|c|c|c|}
\hline Fusion method & Advantage & disadvantage & domain \\
\hline Average Technique [32] & \multirow[t]{4}{*}{$\begin{array}{l}\text { All these techniques are very simple, } \\
\text { easy to calculate } d \text { and implemented }\end{array}$} & $\begin{array}{l}\text { Decrease the quality of resultant image fusion } \\
\text { because this technique added a noise into fused } \\
\text { image. }\end{array}$ & \multirow{7}{*}{$\begin{array}{l}\text { Working on } \\
\text { Spatial } \\
\text { domain }\end{array}$} \\
\hline $\begin{array}{l}\text { Maximum Pixel Value Technique } \\
\text { [32] }\end{array}$ & & \multirow{3}{*}{$\begin{array}{l}\text { These techniques introduced blurred output which } \\
\text { is affect to the contrast of image, so these methods } \\
\text { are not applied into real time applications }\end{array}$} & \\
\hline Minimum Pixel Value Technique [32] & & & \\
\hline Max-Min Pixel Value Technique [32] & & & \\
\hline Weighted average technique [47] & Improves the detection reliability & Increasing SNR of resultant image. & \\
\hline $\begin{array}{l}\text { Principle Component Analysis } \\
\text { Algorithm [45] }\end{array}$ & $\begin{array}{l}\text { Very simple, fast processing, time, } \\
\text { high spatial quality and efficient for } \\
\text { computational }\end{array}$ & Spectral degradation and colour distortion & \\
\hline Brovey technique [48] & $\begin{array}{l}\text { Very simple, fast processing, time, and } \\
\text { efficient for computational . It } \\
\text { introduced RGB image with high } \\
\text { contrast degree. }\end{array}$ & Colour distortion & \\
\hline Laplacian / Gaussian Pyramid [60] & \multirow{3}{*}{$\begin{array}{l}\text { Good visual quality of multi focus } \\
\text { images. }\end{array}$} & \multirow[t]{3}{*}{$\begin{array}{l}\text { All these techniques produce more or less similar } \\
\text { output image. The number of decomposition level } \\
\text { effect on the result of fused image }\end{array}$} & \multirow{3}{*}{$\begin{array}{l}\text { Working on } \\
\text { Frequency } \\
\text { domain }\end{array}$} \\
\hline Ratio of low pass Pyramid [61] & & & \\
\hline Morphological Pyramid [62] & & & \\
\hline Discrete cosine Transform (DCT) [46] & $\begin{array}{l}\text { This method decrease the complexity } \\
\text { and analysis the image into series of } \\
\text { waveform. This technique can be } \\
\text { applied on real applications. }\end{array}$ & $\begin{array}{l}\text { Provide not good quality on image fusion if block } \\
\text { based smaller then } 8 \times 8 \text { or the image size itself. }\end{array}$ & \multirow{4}{*}{$\begin{array}{l}\text { Working on } \\
\text { Frequency } \\
\text { domain }\end{array}$} \\
\hline $\begin{array}{l}\text { Discrete wavelet transform (DWT) } \\
\text { [49] }\end{array}$ & $\begin{array}{l}\text { Introduce good quality resultant } \\
\text { image fusion and high SNR and } \\
\text { decreases the spectral noise }\end{array}$ & The resultant image is less than spatial resolution. & \\
\hline Kekr' Transform [55] & $\begin{array}{l}\text { Generate various variable of KW } \\
\text { transform depending on the size of } \\
\text { Kekre transform }\end{array}$ & & \\
\hline $\begin{array}{l}\text { Stationary wavelet transform (SWT) } \\
\text { [51] }\end{array}$ & $\begin{array}{l}\text { Provide a good result in second level } \\
\text { of decomposition. }\end{array}$ & This method consume a lot of time for calculation. & \\
\hline
\end{tabular}


Table 2 : Full Reference Image quality measurements

\begin{tabular}{|c|c|c|}
\hline Criteria & Definition & Equation \\
\hline $\begin{array}{l}\text { Mean Squared } \\
\text { Error (MSE) } \\
\text { [56] }\end{array}$ & $\begin{array}{l}\text { If the value of mean square is large that means } \\
\text { image quality is a poor. }\end{array}$ & $M S E=\frac{1}{M * N} \sum_{i=1}^{M} \sum_{j=1}^{N}\left(A_{i j}-B_{i j}\right)^{2}$ \\
\hline $\begin{array}{l}\text { Peak Signal to Noise } \\
\text { Ratio (PNSR) [59] }\end{array}$ & The Mean squared error is given by & PSNR $=10 * \log _{10}\left(\frac{\text { peak }^{2}}{\text { MSE }}\right)$ \\
\hline $\begin{array}{l}\text { Root Mean Squared } \\
\text { Error (RMSE)[59] }\end{array}$ & $\begin{array}{l}\text { Are applied to detect the contrast between the } \\
\text { input and the resultant images. Low values of } \\
\text { RMSE signalize that the resultant information is } \\
\text { similar to the input data. }\end{array}$ & RMSE $=\sqrt{\frac{1}{M * N} \sum_{i=1}^{M} \sum_{j=1}^{N}\left(A_{i j}-B_{i j}\right)^{2}}$ \\
\hline $\begin{array}{l}\text { Mutual Information } \\
\text { (MI)[63] }\end{array}$ & $\begin{array}{l}\text { is implemented to calculate the similarity of } \\
\text { intensity between images } A \text { and } B \text {. the value of } \\
I(A, B) \text { is High means the similarity between } A \\
\text { and } B \text { is very close. }\end{array}$ & $\begin{array}{l}M I(A, B)=\sum_{i=1}^{N} P_{A B}(a, b) \frac{\log \left(P_{A B}(a, b)\right)}{\left(P_{A}(a) P_{B}(b)\right)} \\
\text { where } \\
P A B(a, b) \text { is the joint distribution probability, } \\
P A(a) \text { and } P B(b) \text { are the distribution probabilities of } A \text { and } B \text {, } \\
\text { respectively. }\end{array}$ \\
\hline $\begin{array}{l}\text { Structural Similarity } \\
\text { Index Metrics } \\
\text { (SSIM) [59] }\end{array}$ & $\begin{array}{l}\text { is used to estimate the similarity of two images A } \\
\text { and B. } \\
\text { A high value of this index indicates a great } \\
\text { similarity of the two images. }\end{array}$ & $\begin{array}{l}\qquad \operatorname{SSIM}(A, B)=\frac{\left(2 \mu_{A} \mu_{B}+C_{1}\right)\left(2 \sigma_{A B}+C_{1}\right)}{\left(\mu_{A}^{2}+\mu_{B}^{2}+C_{1}\right)\left(\sigma_{A}^{2}+\sigma_{B}^{2}+C_{2}\right)} \\
\text { where } \\
\mu A \text { and } \mu B \text { are the mean intensities, } \sigma A \text { and } \sigma B \text { are standard } \\
\text { deviations, } \sigma A B \text { is the covariance of } A \text { and } B \text {, } \\
C 1 \text { and } C 2 \text { are small constants for } A \text { and } B \text {, respectively. }\end{array}$ \\
\hline
\end{tabular}

Table 3: No reference image quality measurements

\begin{tabular}{|c|c|c|}
\hline Entropy [64] & $\begin{array}{l}\text { Is assessing the quality of image. If the entropy } \\
\text { value is large, } \\
\text { it is an indication that the fusion performance } \\
\text { has progressed. }\end{array}$ & Entropy $=-\sum_{\mathrm{i}=0}^{\mathrm{G}} \mathrm{p}(\mathrm{i}) \log _{2}(\mathrm{p}(\mathrm{i}))$ \\
\hline Spatial Frequency (SF) [63] & $\begin{array}{l}\text { A large value of Spatial Frequency means the } \\
\text { higher clarity of the image. }\end{array}$ & $\begin{array}{l}\mathrm{SF}=\sqrt{\mathrm{Rf}^{2}+\mathrm{CF}^{2}} \\
\text { Where } \\
\mathrm{RF}=\sqrt{\frac{1}{\mathrm{M} * \mathrm{~N}} \sum_{\mathrm{i}=1}^{\mathrm{M}} \sum_{\mathrm{j}=1}^{\mathrm{N}}(\mathrm{I}(\mathrm{i}, \mathrm{j})-\mathrm{I}(\mathrm{i}, \mathrm{j}-1))^{2}} \\
\text { And }\end{array}$ \\
\hline & & $C F=\sqrt{\frac{1}{M * N}} \sum_{i=1}^{M} \sum_{j=1}^{N}(I(i, j)-I(i-1, j))^{2}$ \\
\hline $\begin{array}{l}\text { Standard Deviation(SD) } \\
\text { [65] }\end{array}$ & $\begin{array}{l}\text { is measured on the low frequency of the input } \\
\text { image by using a } 3 \times 3 \text { windows and getting } \\
\text { higher values of mean were selected as the } \\
\text { fusion coefficients of low frequency } \\
\text { components. }\end{array}$ & $\begin{array}{l}S=\frac{1}{M} \sum_{i=1}^{M}\left(B_{i}-\bar{B}\right) \\
\text { Where } \\
\bar{B}=\frac{1}{M} \sum_{i=1}^{M}\left(B_{i}\right)\end{array}$ \\
\hline
\end{tabular}




\section{CONCLUSION}

Different algorithms of spatial and frequency domain theories have been reviewed in this paper. The main purpose of this study is giving a guide for any specialist who wants to work on image fusion. At the beginning, the application to which the image fusion need to be applied must be determined, then the suitable mentioned technique (or techniques) of image fusion can be chosen to give the best result and serve the application. According to the properties of the image fusion techniques, one of them can be chosen according to the highlighted simple comparison of advantage and disadvantage of image fusion methods as shown in Table 1.

The simple fusion algorithms like averaging, minimum, maximum, max-min and Weighted average Technique are producing a noisy, blurred and low contrast image; they cannot be used for real time applications. Principal component analysis (PCA), HPF and Brovey are simple, easy for computational and fast algorithms but these techniques result in colour distortion. The fused image using PCA has high spatial quality but it results in spectral degradation. All pyramid theories depends on Fusion methods introduce more or less similar output. These methods are typically utilized for multi-focus application. Discrete Cosine Transform (DCT) method is used in real time system but cannot be applied with block size less than $8 \times 8$. The DWT algorithm has a high Signal to Noise Ratio and minimum spectral distortion. But, the isotropic property of wavelet techniques which can't be capture the long edge and the curve of the image, make this technique is not suitable for some application. The SWT algorithm can describe of the details components of images and can decompose the details effectively compared to the ordinary wavelet transform. Every technique represents some advantages and drawbacks. Thus, we can deduce that no fusion theory outperforms the others. Some applications need to make Hybrid between these algorithms to get a good resultant image fusion like combination between PCA and discrete wavelet transform (DWT) give a good result and this is served some allocations .

\section{REFERENCES}

[1] B. Panda, " Image Fusion Using Combination of Wavelet And Curvelet Fusion", International Journal of Advanced Research in Computer
Engineering \& Technology (IJARCET), Vol. 5, Issue :8, pp.2316-2324, 2016.

[2] Z. Omar and T.Stathaki, " Image fusion: An overview", ISMS 2014; 5th International Conference on Intelligent Systems Modelling and Simulation, 27-29 Jan.2014, Langkawi- Malaysia, pp. 306-310, Jan 2014.

[3] K.C. Rajini and S. Roopa "A review on recent improved image fusion techniques", (WiSPNET) 2017; International Conference on Wireless Communications, Signal Processing and Networking, 22-24 March 2017, Chennai- India , pp.149-153, 2017.

[4] C.Li and A. Zhu, " Application of image fusion in diagnosis and treatment of liver cancer", Applied Sciences, Vol.0, Issue:3,pp.1171-1199,2020.

[5] C.O. Ancuti, C. Ancuti,C. De Vleeschouwer and P. Bekaert," Color balance and fusion for underwater image enhancement", IEEE Transactions on image processing, Vol.27,Issue:1, pp.379-93, 2017.

[6] J.Zhi-guo, H. Dong-bing, C. Jin and Z. Xiao-kuan, " A wavelet based algorithm for multi-focus microimage fusion", (ICIG'04); Third International Conference on Image and Graphics, 18-20 Dec. 2004, Hong Kong- China, ,pp.176-179, Dec. 2004.

[7] A.Wang and P.Zhao, "Multi-focus Image Fusion with the Double-Density Dual-Tree DWT". Image and Signal Processing, CISP'08, Vol.4, pp.371-374, 2008.

[8] K.P.MHM and M.Seetha, "Comparison of Fuzzy and Neuro Fuzzy Image Fusion Techniques and its Applications", International Journal of Computer Applications, Vol.43,Issue: 20, pp. 31-37,2012.

[9] Y.Sun and L.Jiang, "Color multi-focus image fusion algorithm based on fuzzy theory and dualtree complex wavelet transform", Journal of Algorithms \& Computational Technology, Vol.11,Issue:2, pp.163-9, 2017.

[10] A.G. Mahyari and M.Yazdi, "A novel image fusion method using curvelet transform based on linear dependency test"; ICDIP2009, Digital Image Processing, 2009 International Conference on IEEE, 7-9 March 2009, Bangkok-Thailand , pp.351-354,2009.

[11] S.Li and B.Yang, "Multifocus image fusion using region segmentation and spatial frequency". Image and Vision Computing, Vol. 26, Issue:7,pp. 971979,2008.

[12] FP.Pai, LJ.Yang, L and Y.C.Chung, " Multi-layer ontology based information fusion for situation awareness", Applied Intelligence,Vol. 46, Issue:2, pp.85-307,2017.

[13] N.Mitianoudis, T.andtathaki, "Pixel-based and regionbased image fusion schemes using ICA bases", Information Fusion, Vol. 8, Issue:2,pp. 131142,2007

[14] T.Zaveri, M. Zaveri, V.Shah and N.Patel, " A novel region based multifocus image fusion method", ICDIP 2009; International Conference on Digital Image Processing, 7-9 March 2009, Bangkok-Thailand, pp.50- 54,2009. 
[15] G.Ravikanth, K.V.Sunitha and BE.Reddy, "A Novel Region Segmentation-Based Multi-focus Image Fusion Model"; ICCIDE 2018, International Conference on Computational Intelligence and Data Engineering ,28-29 Sep. 2018,,Singapore ,,pp. 247-264, 2018.

[16] J.J. Lewis, R.J. O'callaghan, S.G. Nikolov, D.R. Bull and C.N.Canagarajah, "Region-based image fusion using complex wavelets"; FUSION 2007, Seventh International Conference on Information Fusion, 28June-1July 2004, Stockholm-Sweden, pp. 555-562.2004.

[17] H.B. Kekre, D.Mishra and R.Saboo, "Review on image fusion techniques and performance evaluation parameters", International Journal of Engineering Science and Technology IJEST, Vol.5, Issue:4, pp.880-889,2013.

[18] KY.Tien, H.Samani and JH.Lui, "A survey on image processing in noisy environment by fuzzy logic"; CACS 2017, image fusion, neural network, and non-local means, IEEE International Automatic Control Conference ,13-16 Nov. 2017, Pingtung-Taiwan, pp. 1-6,2017.

[19] JS. Kulkarni and RS. Bichkar, " Optimization in Image Fusion Using Genetic Algorithm", International Journal of Image, Graphics and Signal Processing, Vol.11, Issue:8, pp.50-59,2019.

[20] M. Amin-Naji and A. Aghagolzadeh, "Multi-focus image fusion in DCT domain using variance and energy of Laplacian and correlation coefficient for visual sensor networks", Journal of AI and Data Mining, Vol. 6 ,Issue:2, pp.233-50, 2018.

[21] MN. Narsaiah, S.Vathsal and D.V.Reddy, "A Survey on Image Fusion Requirements, Techniques, Evaluation Metrics, and Its Applications", International Journal of Engineering \& Technology, Vol.7, Issue:2.20 , pp.260266,2018.

[22] C. Deng,Z.H.Wang,X.W. Li, H.N. Li, and C.C. Cavalcante," An Improved Remote Sensing Image Fusion Algorithm Based on IHS Transformation", KSII Transactions on Internet \& Information Systems, Vol.11,Issue:3 ,pp. 1633-1649, 2017.

[23] X.Yang, J.Wang and R.Zhu," Random walks for synthetic aperture radar image fusion in framelet domain", IEEE Transactions on Image Processing,Vol. 27,Issue:2,pp. 851-65,2017.

[24] B.Meher, S.Agrawal, R.Panda and A. Abraham, "A survey on region based image fusion methods". Information Fusion, Vol. 48, pp.119-32, 2019.

[25] A.Mookambiga and V.Gomathi, "Comprehensive review on fusion techniques for spatial information enhancement in hyperspectral imagery" , Multidimensional Systems and Signal Processing, Vol.27,Issue :4, pp.863-89,2016.

[26] P.Panyala and Y.T.Rathod, "Image Denoicing Using Fusion Techniques Based on Dwt Coefficients Image Denoicing Using Fusion Techniques", Studies in Indian Place Names, Vol.40, Issue:9, pp.84-90,2020.

[27] J.Yadav, A.Dogra, B. Goyal and S.Agrawal, "A review on image fusion methodologies and applications". Research Journal of Pharmacy and Technology, Vol.10, Issue:4, pp.1239-1290, 2017.
[28] D.Mishra and B.Palkar, " Image Fusion Techniques: A Review", International Journal Of Computer Applications (0975 - 8887), Vol. 130, Issue:9, pp.7-13,2015.

[29] A.Dogra, B.Goyal and S.Agrawal, "From multiscale decomposition to non-multi-scale decomposition methods: a comprehensive survey of image fusion techniques and its applications", IEEE Access, Vol.5, pp.16040-67, 2017.

[30] S. Masood, M. Sharif, M.Yasmin, M.A. Shahid and A. Rehman," Image Fusion Methods: A Survey", Journal of Engineering Science \& Technology Review, Vol.10, Isuue:6, pp. 186-1922017.

[31] M. Amin-Naji, A.Aghagolzadeh A and M.Ezoji, "Ensemble of CNN for multi-focus image fusion", Information fusion, VolNo..1,51,pp.201-14, 2019.

[32] M.Sharma, "A Review : Image Fusion Techniques and Applications", (IJCSIT) International Journal of Computer Science and Information Technologies, Vol.7, Issue:3 ,pp.1082-1085,2016.

[33] C.Du and S.Gao, " Image segmentation-based multi-focus image fusion through multi-scale convolutional neural network", IEEE access, Vol.5, pp.15750-15811,2017.

[34] P.Pimpalkar, V.Thombre, T.Salve, S. Ingle and A.R.Dandekar, "Image Fusion Techniques and Applications: A Review", International Journal on Future Revolution in Computer Science \& Communication Engineering, Vol. 4, Issue:2,pp. $472-475,2018$.

[35] A.Sharma and A.Saroliya, "A Brief Review of Different Image Fusion Algorithm", International Journal of Science and Research (IJSR),Vol. 4, Issue:6, pp.2650-2651, 2015.

[36] C.Kwan, B.Chou, LY.Kwan, J.Larkin, B. Ayhan, JF.Bell and H.Kerner, "Demosaicing enhancement using pixel-level fusion", Signal, Image and Video Processing, Vol.12, Issue:4, pp.749-56, 2018.

[37] G.Verhoeven, M.Nowak and R.Nowak, "Pixellevel image fusion for archaeological interpretative mapping"; ARQUEOLÓGICA 2.0, 8th International Congress on Archaeology, Computer Graphics, Cultural Heritage and Innovatio ,5-7 Sep.2016,Valencia -Spain, pp. 404-407,2016.

[38] B.Panda and R.Khare, "Survey on Image Fusion Using Combination of Wavelet And Curvelet Fusion". Journal of Emerging Technologies and Innovative Research (JETIR), Vol. 3, Issue:4, pp.278-282,2016.

[39] M. Abdipour and M. Nooshyar, " Multi-focus image fusion using sharpness criteria for visual sensor networks in wavelet domain", Computers \& Electrical Engineering,Vol. 51, pp.74-88,2016.

[40] R.Sivagami, V.Vaithiyanathan, V.Sangeetha, M.Ifjaz Ahmed, K.Joseph, S. Abraham and K.Divya, "Review of Image Fusion Techniques and Evaluation Metrics for Remote Sensing Applications", Indian Journal of Science and Technology, Vol.8, Issue:35, pp.1-7, 2015.

[41] Komal, Dewan ,R., "Energy Based Wavelet Image Fusion", IJIRST -International Journal for Innovative Research in Science \& Technology, Vol. 1, Issue:6, pp.6-13,2014. 
[42] C.Qiu, J.Wei and Q.Dong, "Research of Image Fusion Method about ZY-3 Panchromatic Image and Multispectral Image"; EORSA 2018, Fifth International Workshop on Earth Observation and Remote Sensing Applications,18-20 June 2018, Xi'an- China, pp. 1-5,2018.

[43] SK.Verma, M.Kaur and R.Kumar, "Hybrid image fusion algorithm using Laplacian Pyramid and PCA method"; ICTCS'16, Second International Conference on Information and Communication Technology for Competitive Strategies, 4-5 Mar.2016, Udaipur-India,pp. 1-6,2016.

[44] Z. Gao, H.Z. Xuan, H.Zhang, S. Wan and KK.Choo, "Adaptive fusion and category-level dictionary learning model for multiview human action recognition", IEEE Internet of Things Journal, Vol6, No.6, pp.9280-93, 2019.

[45] Y. Li, X.Shen and H.Chen, "Pyramid Pooling Dense Convolutional Neural Network for Multifocus Image Fusion"; CCIS 2019, IEEE 6th International Conference on Cloud Computing and Intelligence Systems, 25-27 DEC. 2019, Singapore, pp.164-168,2019.

[46] Y. Liu, X.Chen, H. Peng and Z.Wang, " Multifocus image fusion with a deep convolutional neural network ", An International Journal on Multi-Sensor, Multi-Source Information Fusion, Vol.36, Issue:(C),pp. 191-207,2017.

[47] S. Li, X. Kang and H. Jianwen, "Image fusion with guided filtering", Image Processing, IEEE Transactions ,Vol. 22, Issue:7, pp. 28642875,2013

[48] Y.Liu, X.Chen, RK.Ward and ZJ.Wang, "Medical image fusion via convolutional sparsity based morphological component analysis", IEEE Signal Processing Letters Vol.26, No.3,pp:485-9,2019.

[49] S.Sharma, JJ.Zou and G.Fang, "Contrast enhancement using pixel based image fusion in wavelet domain"; IC3I 2013,2nd International Conference on Contemporary Computing and Informatics, 14-17 Dec. 2016 , India, pp. 285$290,2016$.

[50] S.Li, X.Kang, L.Fang, J.Hu and H.Yin, "Pixel-level image fusion: A survey of the state of the art", information Fusion, Vol.33, pp.100-112, 2017.

[51] X.Li, L.Wang, J.Wang and X.Zhang, "Multi-focus image fusion algorithm based on multilevel morphological component analysis and support vector machine", Iet Image Processing, Vol.11, Issue:10, pp.919-926, 2017.

[52] RR.Nair and T.Singh, "Multi-sensor medical image fusion using pyramid-based DWT: a multiresolution approach", IET Image Processing, Vol. 13, Issue:9, pp.1447-1506,2019.

[53] B. Rajalingam and R. Priya, "Combining multimodality medical image fusion based on hybrid intelligence for disease identification", International Journal of Advanced Research Trends in Engineering and Technology, Vol. 5, Issue:12, pp.862-887,2018.

[54] R.Dhannawat, T.Sarode, H.BKekre, "kekre's hybrid wavelet transform technique with dct, walsh, hartley and kekre's transform for image fusion", international journal of computer engineering \& technology (IJCET), Vol.4, Issue:1, pp.195-202,2013.

[55] B. Rajalingam and R.Priya, "Multimodal medical image fusion using various hybrid fusion techniques for clinical treatment analysis", Smart Construction Research, Vol. 2, Issue :2, pp.1-2018.

[56] C. Berger, M. Voltersen, R. Eckardt, J. Eberle, T. Heyer, N. Salepci, S. Hese, C. Schmullius, J. Tao, S. Auer and R. Bamler, "Multi-modal and multitemporal data fusion", IEEE Journal of Selected Topics in Applied Earth Observations and Remote Sensing, Vol. 6, Issue:3, pp.1324-1340,2013.

[57] P.D.Vora, N.Chudasama, "Different Image Fusion Techniques andParameters: A Review", (IJCSIT) International Journal of Computer Science and Information Technologies, Vol.6, Issue:1, pp.889892, 2015.

[58] P.Hill, ME. Al-Mualla, D.Bull, "Perceptual image fusion using wavelets", IEEE transactions on image processing, Vol.26, Issue:3, pp.1076-88, 2016.

[59] G.Babu and R.Sivakumar, "Comparative Analysis of MRI-PET Brain Image Fusion Using Discrete Wavelet Transform";ICGSP'17, International Conference on Graphics and Signal Processing, 2427June 2017, Singapore- Singapore, pp. 48-54, 2017.

[60] T. Saikumar, S.Venkatesh, MA.Uddin, "Comparison Techniques of Image Fusion in Image Segmentation", International Conference on Computer \& Communication Technologies 2K14, Vol.3, Issue.1,pp:378-381, March 28-29, 2014.

[61] V. Gupta, and S. Mehra, "Image Fusion Techniques-A Comparative Study", International Journal of Engineering Trends and Technology (IJETT),Vol.32, No.2,pp:113-118,February 2016.

[62] S. S. Bedi and R. Khandelwal, "Comprehensive and Comparative Study ofImage Fusion Techniques", International Journal of Soft Computing and Engineering (IJSCE), Vol.3, Issue.1,pp:300304, March 2013.

[63] L.Zhan, Y.Zhuang, L.Huang, "Infrared and visible images fusion method based on discrete wavelet transform", J. Comput, Vol. 28, Issue:2, pp.57$71,2017$.

[64] SK.Panguluri and L.Mohan, "Discrete Wavelet Transform Based Image Fusion Using Unsharp Masking", Periodica Polytechnica Electrical Engineering and Computer Science, Vol. 64, Issue:2, pp.211-231,2020.

[65] R.Gharbia, AE.Hassanien, AH.El-Baz, M. Elhoseny and M.Gunasekaran, "Multi-spectral and panchromatic image fusion approach using stationary wavelet transform and swarm flower pollination optimization for remote sensing applications", Future Generation Computer Systems, Vol. 88,Issue:, pp. 501-512.

[66] S.Aymaz and C.Köse, "Multi-focus image fusion using stationary wavelet transform (SWT) with principal component analysis (PCA) "; ELECO 2017, 10th International Conference on Electrical 
and Electronics Engineering, 30 Nov-2Dec. 2017 Bursa-Turkey, pp. 1176-1180,2017.

[67] T.Lianfang, J.Ahmed, D.Qiliang, B.Shankar and S.Adnan, "Multi focus image fusion using combined median and average filter based hybrid stationary wavelet transform and principal component analysis", International Journal of Advanced Computer Science and Applications, Vol. 9, Issue:6, pp.34-41,2018.

[68] JS.Kulkarni and RS.Bichkar, " Comparative Analysis of Image Fusion Using DCT, DST, DWT, Walsh Transform and Kekre's Wavelet Transform"; ICICA 2018, InInternational Conference on Intelligent Computing and Applications , , 8-10 Jan 2018, Singapore, pp. 227235, 2018.

[69] B.Palkar and D.Mishra, "Fusion of multi-modal lumbar spine images using Kekre's hybrid wavelet transform", IET Image Processing,Vol. 13, Issue:12, pp.2271-2351,2019.

[70] S.S.Bedi, J.Agarwal and P. Agarwal, "Image Fusion Techniques and Quality Assessment Parameters for Clinical Diagnosis: A Review" ,International Journal of Advanced Research in Computer and Communication Engineering, Vol. 2, Issue:2, pp.1153-1157,2013.

[71] J.Kim and Lee, " S. Fully deep blind image quality predictor", IEEE Journal of selected topics in signal processing, Vol. 11, Issue:1, pp.206-226,2016.

[72] A.Saha and Q.J. Wu, "Full-reference image quality assessment by combining global and local distortion measures", Signal Processing, Vol. 128, pp.186-97,2016.

[73] I.T. AHMED, C.S.Der and B.T.A HAMMAD, "Survey of Recent Approaches on No-Reference Image Quality Assessment with Multiscale Geometric Analysis Transforms ",International Journal of Scientific \& Engineering Research, Vol. 7, Issue:12, pp.1146-1155,2016.

[74] K.Kalaivani and Y.A. Phamil, "Analysis of Image Fusion Techniques based on Quality Assessment Metrics", Indian Journal of Science and Technology, Vol.9, Issue:31, pp.1-8,2016.

[75] P.Jagalingam and A.V.Hegdeb, " A Review of Quality Metrics for Fused Image"; ICWRCOE 2015, International Conference on Water Resources, Coastal And Ocean Engineering,12-14 Mar. 2015, Mangalore-INDIA, pp. 133 - 142, 2015.

[76] V.T.Manu and P.Simon, "A novel statistical fusion rule for image fusion and its comparison in non subsampled contourlet transform domain and wavelet domain", The International Journal of Multimedia \& Its Applications (IJMA),Vol.4, Issue:2, pp, 69-87,2012.

[77] A. Asokan and J.Anitha, "Satellite Image Enhancement Using Hybrid Denoising Method for Fusion Application"; ICCAN 2020, International Conference on of Computing, Analytics and Networking, 7-15 Feb., Singapore-Singapore, 2020, pp. 115-123,2020.

[78] H.Song, Q. Liu, G.Wang, R.Hang and B.Huang, "Spatiotemporal satellite image fusion using deep convolutional neural networks", IEEE Journal of
Selected Topics in Applied Earth Observations and Remote Sensing , Vol. 11, Issue:3, pp.821830,2018.

[79] K.RaiK, A.Rai, K.Dhar, J.Senthilnath, SN.Omkar and KN.Ramesh, "SIFT-FANN: An efficient framework for spatio-spectral fusion of satellite images", Journal of the Indian Society of Remote Sensing, Vol. 45, Issue:1, pp.55-65,2017.

[80] A.YOUSIF ,ZB.Omar, UU.Sheikh, "A Survey on Multi-Scale Medical images Fusion Techniques: Brain Diseases", Journal of Biomedical Engineering and Medical Imaging, Vol.7, Issue:1,pp.18-38,2020.

[81] P.Ghamisi, B. Rasti, N. Yokoya, Q. Wang, B. Hofle, L.Bruzzone, F.Bovolo, M.Chi, K. Anders, R.Gloaguen, PM.Atkinson, " Multisource and multitemporal data fusion in remote sensing ", IEEE Geoscience and Remote Sensing Magazine, Vol. 7 , Issue:1, pp.6-39,2019.

[82] H. Li, X.He, D.Tao, Y.Tang and R.Wang, "Joint medical image fusion, denoising and enhancement via discriminative low-rank sparse dictionaries learning", Pattern Recognition, Vol. 79, pp.13046,2018.

[83] P.Ganasala and AD.Prasad, "Medical image fusion based on Frei-Chen masks in NSST domain";SPIN 2018; SPIN 2018, 5th International Conference on Signal Processing and Integrated Networks, 2223Feb. 2018, Noida-Delhi-NCR, pp. 619623,2018

[84] S.Chen, W.Wang and H.Liang. "Evaluating the effectiveness of fusing remote sensing images with significantly different spatial resolutions for thematic map production";PCE 2019; Physics and Chemistry of the Earth, Parts A/B/C. 2019, pp.71$80,2018$. 


\section{دراسة عامة عن دمج الصور الرقمية وتطبيقاتها

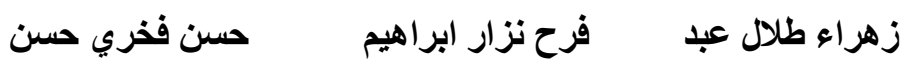 \\ جامعة الموصل ـ كلية الهندسة ـ قسم هندسة الحاسوب \\ zahraatalal@umosul.edu.iq}

يتم تطبيق دمج الصور الرقمبة لاستعادة مجموعة من البيانات من صورتين أو أكثر من صورتبن ووضعها في صورة واحلة لإنشا

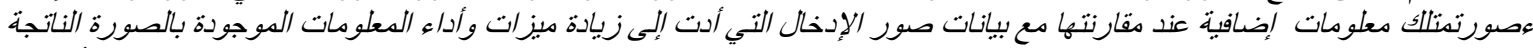

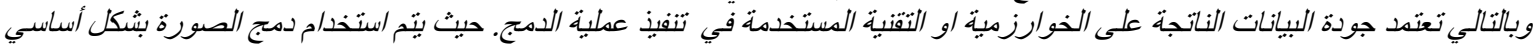

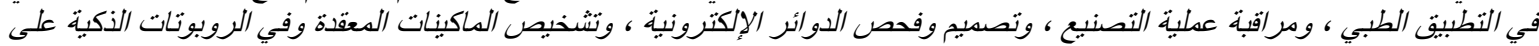

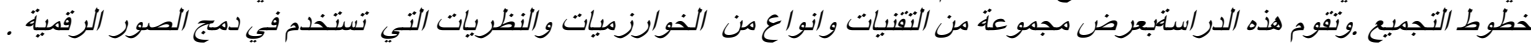

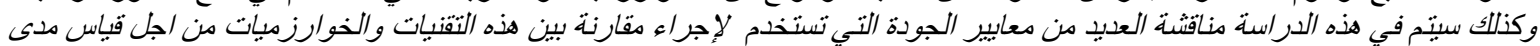

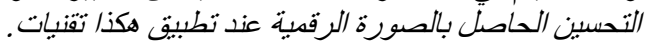
أكلمات الدالهه : دمج الصور ،التحويل المويجي المقطع، التحويلات المويجات الثابتة، تحويلات الجيب تمام الدقطعة ، تحليات المكون الرئبسي. 